\title{
Structural relationship between the motivation to study of the second language (De), stability and the second language knowledge
}

\author{
Gulzhan Isatayeva - Ileshan Smanov - Dinara Mutanova - Nursaule \\ Aytbayeva - Zhanar Saduova - Saltanat Beissembayeva
}

DOI: 10.18355/XL.2018.11.03.14

\begin{abstract}
The aim of the study is to point out the structural relationships between the possession of a second language and the construction of the stability, motivation and demotivation of students of the second language. The study involved 168 students in Ahmet Yassawi International Kazakh-Turkish University. The data were analyzed using factor analysis, correlations and modeling of structural equations (SEM). Seven factors of sustainability (life satisfaction, communicative, communicative effectiveness, self-control, strategic competence, metacognitive adaptation and realistic optimism) were determined in factor analysis, six factors of motivation (it should be in the second language, ideal second language, instrumental motivation, parental support, academic motivation, awareness of importance) and six factors of demotivation (negative perception of English-speaking countries, compulsory EFL education, perception of irrelevance textbooks or problems, low self-esteem, inappropriate learning environment, untrained teachers). The modeling of structural equations confirmed that stability, the motivation of the second language and the demotivation of the second language contribute to an increase in the level of proficiency in the second language. demotivation of the second language was more explanatory for the possession of a second language than the motivation for learning a second language. Stability had both direct and indirect influence on the knowledge of the second language through the demotivation of the second language. The findings indicate that teachers should equip students with coping strategies for learning a second language.
\end{abstract}

Key words: sustainability, demotivation, motivation, second language proficiency, English as a foreign language

\section{Introduction}

In the area of L2 education, the role of motivation in achieving the second language of students (L2) was widely discussed (Do"rnyei and Ushioda 2013, Gardner 2001, 2010). However, in the context of the English as a foreign language (EFL), the binding nature of the academic context was identified as the main DE motivator, as a result of which students lose interest in learning L2 (Kikuchi 2013, Sakai and Kikuchi 2009). The dynamic interaction between motivation and demotivation implies that the impact on L2 training goes beyond simple motivation and demotivation as such (Kikuchi 2015), including maintaining the interest of L2 students in studying L2 in different educational contexts.

One approach to restoring students' interest in studying L2, the role of sustainability, the ability to recover from adversities, has attracted the attention of scientists (Martin and Marsh 2009, Oxford et al., 2007). The concept of sustainability was first introduced in the field of psychiatry to help those who are struggling with chronic diseases (Cicchetti 2010, Connor and Davidson 2003). In the process of learning the language, students must deal with various difficulties, such as unwanted assessments and failure in communication. In particular, for EFL students who do not see the immediate advantages of learning English in everyday life, deftly managing such difficulties is an important task that they need to perform in order to achieve the desired level of L2 mastery. For example, for university students in Ahmet Yassawi 
International Kazakh-Turkish University (hereinafter referred to as IKTU) who participate in compulsory English classes as a requirement for graduates who are assigned to a class without regard to their personal preferences or the level of motivation for L2 education and L2 qualifications.

Although the concept of sustainability is important from the point of view of its role in teaching EFL, it has not been widely accepted or discussed in the field of research. Studies on sustainability in the context of L2 training are in the making (Oxford 2016), and there is a need to evaluate the theoretical validity of the design for a large number of participants. In addition, the dynamics of sustainability, the motivation for learning L2 and the demotivation of learning L2 require research to study their structural relationships. In the light of previous studies on secondary school students, expanding the scope of study for university students can shed light on the role of sustainability in motivating students to learn L2, L2 learning demotivation, and L2 knowledge.

To this end, the present study is aimed at identifying factors that create a motivation for learning L2, demotivating learning L2 and sustainability. In addition, the structural relationship between these constructs and the level of knowledge of L2 was investigated by modeling structural equations (SEM).

\section{Literature review}

Motivation for Learning L2 In previous studies, various efforts have been made to conceptualize motivation for learning L2 (Do“rnyei and Ushioda 2013, Gardner 2010, Kormos et al., 2011). One approach is that the L2 Do "rnyei's motivation system (2009). The basic assumption of this system is that students make efforts to study L2 in order to narrow the gap between their current status and the desired future self. Inside this system there are two self-educations, namely the ideal L2-i and should be L2-i. The ideal L2 itself refers to the aspirations of a person associated with L2 training, for example, to become a competent member of the L2 community, reaching a high level of L2 skill. Loving L2 reflects a sense of duty and / or concern about learning a language. Empirical studies have shown support for the positive role of ideal L2-itself in learning L2 (Kormos et al., 2011) and L2 proficiency (Lamb 2012).

In addition to the internal self-system, the cognitive process of converting goals into behavior also received academic attention. Higgins (1998) proposed a theory of self-regulation, which includes two types of regulation: promotion and prevention. People who are career oriented are more sensitive to the potential positive results of L2 training, whereas those who are focused on prevention are more concerned with avoiding the troubles that may arise as a result of not studying L2. For example, if a student continues to study for L2, mainly because of fears that he did not live up to his parents' expectations, the behavior of the student is affected by preventive regulation.

Empirical studies have confirmed the positive role of the promotionoriented regulation in the L2 qualification (Taguchi et al., 2009).

Parent involvement was also discussed as a motivation in the training of L2 (Csize'r and Kormos 2009, Dika and Singh 2002, Kormos et al., 2011). L2 students can get support and support from their parents who believe that L2 training is important, regardless of whether they themselves can speak L2. Parental support may have a direct or indirect impact on the education of L2 students. In this context, Kim and Lee (2014) conducted a study among secondary school students, including all of the motivations for L2 education discussed above: the ideal self-determination of L2 should be for L2, focused on achieving the goal, focused on prevention of funds and parental involvement.

XLinguae, Volume 11 Issue 3, June 2018, ISSN 1337-8384, eISSN 2453-711X 
In general, high school students had significantly higher L2 motivation than secondary school students in terms of ideal and level of L2, the influence of family members and the regulation of progress.

Among high school students, the ideal L2 itself was the most dominant factor in motivating L2 training. On the contrary, incentive-oriented regulation was the most dominant factor among high school students.

\section{L2 Training demotivation}

In the context of EFL, where English is studied as an academic subject, students' interest in learning another language continues to decline: from primary school to high school (Kikuchi 2013, Kim 2012, Pintrich 2003, Sakai and Kikuchi 2009). Recently, the concept of demotivation has been discussed in the context of EFL, where it can be difficult to see directly the extra-curricular benefits of language learning (Kikuchi 2015).

Previous studies on L2 demotivation were aimed at identifying demotizing factors (Falout et al., 2009). One source of demotivation for learning L2 occurs within students. Attributive factors of students, including a low level of self-esteem, lack of self-confidence and feelings of inferiority in comparison with classmates, were identified as dominant demotivating factors (Falout et al., 2009; Sakai and Kikuchi 2009; Trang and Baldauf, 2007). Studies conducted among university students showed that negative self-esteem of an individual, based on evidence of self-esteem or lack of self-confidence, can be demotivational (Jung 2011). Previous students experience of failure or lack of improvement was identified as the source of individual demotivation (Trang and Baldauf 2007).

The studied human experience and the influence of socio-educational factors on it were also widely discussed as a demotivating factor at the individual level. This includes instructor-related elements, such as teaching methods (for example, grammar-based or teacher-oriented) and misconduct of trainers (for example, serious student criticism) (Falout et al., 2009; Sakai and Kikuchi 2009). Textbooks on grammar and inappropriate learning environments were also discussed as demotivating factors (Kikuchi 2015). University level students have identified harsh criticism of their teachers for student errors (Kikuchi 2015) and exam-oriented training without meaningful classroom occupations (Jung 2011) as additional demotivating factors.

\section{Sustainability}

Sustainability is a psychological mechanism by which a person adapts to circumstances despite difficulties (Luthar et al., 2000). This refers to a person's mental ability to overcome stress and cope with difficulties in a positive, constructive way. Those who have stability can recover when faced with difficulties. Previous studies focused on creating sustainability, and it was found that it covers subcomponents, from psychological factors to social relations (Masten et al., 2011).

Addressing as a transitional has been discussed as an important element of sustainability (Cicchetti 2010). When a person interprets a difficulty as a passing one and has a positive outlook on the future, he or she has a chance to overcome unhappiness. Perseverance, the desire to remain on the task and, ultimately, to solve it, is another component constituting sustainability (Maddi 1999). Self-control is also seen as a subcomponent that promotes human resilience (Martin and Marsh 2009). In addition to the individual psychological system, relationships with other people and communication skills have also been widely recognized as important components of sustainability (Olsson et al., 2003). When people communicate and have stable and positive relationships with others, they can share their difficulties and find appropriate social support that can help in overcoming difficulties.

As the substructures of sustainability in education were studied, the impact of resistance to specific academic disciplines began to acquire academic attention. In a 
small number of studies, the effect of resistance on L2 training was investigated. For example, a study by Kim and Li (2014) among secondary school students in IKTU showed that sustainability can affect the motivation and demotivation of L2 education and can have a positive impact on the level of knowledge of L2 students. In addition, identified five factors of sustainability among secondary school students in IKTU, namely, awareness of happiness, empathy, sociability, perseverance and selfregulation. Among them, perseverance had the strongest impact on the level of knowledge of L2 students.

\section{The relationship between the motivation for learning $L 2$}

L2 Learning Demotivation and Resilience Based on the theoretical relationship between individual variables and the achievement of L2, previous empirical studies have examined the relationship between different individual differences, such as the motivation for learning L2 (Kim 2012, Lamb 2012), L2 demotivation (Hu 2011), sustainability (Kim and Lee 2014) and L2 training. For example, a structural model using schoolchildren has shown that demotivating factors that have difficulties with learning L2 and have no interest have a direct and indirect influence on the achievement of L2, which is measured by internal assessments. Also, a dynamic relationship between the motivation for learning L2 and demotivation was proposed (Sakai and Kikuchi 2009). In addition, the impact of sustainability on the motivation and demotivation of L2 training was investigated in a study by Kim and Lee (2014). Regression analysis conducted during this study of high school students showed that sustainability can affect the motivation of learning and demotivation of L2.

However, few studies have attempted to investigate the complex relationship between the motivation for learning L2, demotivation, resilience and L2 skills through a more systematic approach. Most previous studies have used regression analysis (for example, Hu 2011, Kim and Lee 2014); some of them carried out the structural equation of modeling. Given the dynamic interaction between the motivation for learning L2, demotivation, resilience and L2 skills, a more structured and comprehensive approach is clearly needed. This can be achieved using the modeling of structural equations (SEM) to investigate different relationships (Plonsky, 2015). Therefore, this study will investigate the structural relationship between them using SEM. The research objectives are as follows:

1 What are the subcomponents of L2 training motivation, L2 training demotivation and sustainability?

2 What are the structural relationships between the motivation for learning L2, the demotivation of learning L2, the sustainability and English proficiency among EFL students at the university level?

\section{Methodology}

The Context of Learning L2 in IKTU. In the Kazakhstan education system, universities and universities have different approaches to learning English. The main reason that a high school student learns English is to get good grades and earn a place in a prestigious university (Jung 2011). When studying English, high school students pay more attention to grammar, vocabulary and reading comprehension, preparing for the College Skills Exam (CSAT). They take English lessons as part of their compulsory curriculum and tend to become competitive. For university students, the goal of English is to improve the practical English language skills for international communications that are required by most companies. They are very interested in getting high scores on standardized tests in English, such as TOEIC and TOEFL, to find a good job (Shakh 2016). Participants In this study, 168 students from the undergraduate program of IKTU. The main campus of the University had higher academic admission standards for students. The choice of allowed us to examine

XLinguae, Volume 11 Issue 3, June 2018, ISSN 1337-8384, eISSN 2453-711X 
participants with varying degrees of L2 qualifications. Participants were enrolled in compulsory English language courses taught by native speakers of English. With regard to gender distribution, 72 students were men (42.7\%) and 96 women (57.3\%). Two participants did not submit their gender. Of the 168 participants, $93 \%$ were 19 year-old freshmen; average age was 19.22 years.

\section{Data collection and analysis}

After receiving the IRB approval, the data collection for this study took place in September 2016, at the beginning of the new student semester. In order to attract participants, we contacted the instructors in charge of the 41 compulsory EFL class on two campuses. We explained the purpose of the study to both teachers and students and obtained permission to collect data using a questionnaire distributed among 964 students. They were also informed that they can refuse to study at any time and for any reason. Of these, 7 returned questionnaires with empty items or the same answer for each subject. They were excluded from the analysis, leaving 168 participants, as indicated above.

The Questionnaire distributed among the participants consisted of four sections focused on (1) L2 training motivation, (2) L2 learning demotivation, (3) sustainability, and (4) personal information such as age, gender, academic major and Knowledge of English. With the exception of the items in the personal information section, all subjects required a response on a five-point Likert scale, beginning with categorical disagreement (1), in order to fully agree (5). The questionnaires were written in Russian, in the first language of the participants.

The first section was intended for five components of the motivation for learning L2 (ideal self-determination of L2, self-esteem for L2, promotion, prevention and influence of the family) using 39 items (Do"rnyei 2009; Higgins 1998; Kim $2012 \mathrm{a}, \mathrm{b})$. The second part of the questionnaire is aimed at demotivating L2 training (Do"rnyei 2009, Taguchi et al., 2009). A total of 24 subjects concerned the teacher's negative influence, improper training conditions and materials, a negative attitude towards the target language and community and the mandatory nature of the L2 education. 27 points measuring the elasticity in the third section of the questionnaire were based on the work of Shin et al. (2009).

To measure the L2 skill, participants were asked to give their CSAT scores. The test consists of 45 questions with several options, which include 17 questions of hearing perception and 28 questions of understanding readability. The test is considered a comprehensive and reliable measure of the level of English language proficiency of students before they enter the university (Kim 2015). Moreover, the survey was conducted during the first English class, which these students took at the university, as part of their compulsory curriculum. For this reason, this study used CSAT students' assessments to assess their English proficiency.

\section{Data analysis}

In this study, three methods of data analysis were used to identify factors in motivation, demotivation and resistance to L2, and to identify the structural relationships between the designs of each. First, to solve the research question concerning motivation structures, demotivation and resistance to L2, the analytic factor analysis of Oblimin was carried out using the SPSS version

23.0. Also, the internal reliability of each variable was checked. To solve the second question of the study related to T.-Y. Kim et al., Structural relationships between variables, a correlation analysis between the motivation for learning L2, the demotivation of learning L2 and stability was carried out as a first step.

Initially, to verify the conceptual independence of motivation, demotivation and resistance to L2, the Confirmatory Factor Analysis (CFA) was conducted using AMOS version 23.0. Subsequently, modeling of structural equations (SEM) was 
constructed to construct an adequate model. SEM allows you to analyze the interrelated relationship between the constructions of motivation, demotivation and resistance to L2, and also to represent the variables that make up these constructions (Plonsky 2015). This study uses SEM to illustrate the complex and multiple relationships between constructs and variables.

\section{Results}

Factors in Learning Motivation L2 A total of 39 questions in the questionnaire are aimed at motivating L2 training. Factor analysis revealed six factors in the motivation for learning L2, which is $61.45 \%$ of the difference. The factors were (1) should - L2 yourself (15 subjects), studying English for external reasons, for example, getting high scores or recognition from parents; (2) the ideal L2 self (seven items), waiting to speak fluent English in the future; (3) instrumental motivation (seven subjects), expectation of getting a better job with L2 skills; (4) parental support (five subjects), parental encouragement for studying EFL; (5) an academic task (two subjects) using English as a tool for studying academic problems; and (6) awareness of importance (three subjects), awareness of the importance of EFL training. It should be noted that the factor of the "academic problem" $(\mathrm{a}=.53)$ did not reach the reliability factor of 0.60 ; thus, he represented a relatively low internal consistency (Dörnyei 2007).

\section{Factors in Learning L2}

Demotivation. To identify the factors associated with the demotivation of the L2 training experienced by these EFL students, data from 24 points passed factor analysis, identifying six factors in L2 demotivation, which is $60.86 \%$ of the difference: (1) compulsory EFL training (five subjects), reluctance to learn EFL; (2) negative perception of English-speaking countries (four subjects), rejection of English-speaking countries or people; (3) an inappropriate learning environment (three subjects), breaks between other students, or the context of learning; (4) the inappropriateness of textbooks or assignments (four subjects) is perceived, a sense of boredom and difficulty with EFL classes or textbooks; (5) low self-esteem (five subjects), feelings of anxiety, insecurity or anxiety during EFL classes; and (6) untrained teachers (three subjects), unclear or difficult explanations from instructors.

\section{Sustainability Factors}

The results of factor analysis with data from 27 sustainability questionnaires confirmed seven factors, accounting for $58.5 \%$ of the variance. Factors were (1) satisfaction with life (six subjects), a sense of satisfaction of life and gratitude in general; (2) self-control (four subjects), a sense of control over negative feelings; (3) communicative effectiveness (four subjects), a feeling of sympathy for other people; (4) sociability (three subjects), stable relationships with friends; (5) metacognitive adaptation (four subjects), the propensity to strategically solve problems; (6) strategic competence (three subjects), effective communication skills; and (7) realistic optimism (three subjects), attitude to positive results of efforts.

\section{Analysis of the correlation among the learning $L 2$}

Motivation, demotivation and sustainability. As a first step in the study of the structural relationships between variables, Pearson's correlation analysis for L2 qualification and factors identified in motivation, demotivation and learning stability (L2) were conducted (see Table 1). Significant positive correlations were observed between the motivation of learning L2 and the factors of stability. However, selfservice and parental support for L2 showed a significant negative correlation with three factors of elasticity. Regarding the relationship between demotivation and the sustainability of L2 training, the factors of L2 training demotivation showed

XLinguae, Volume 11 Issue 3, June 2018, ISSN 1337-8384, eISSN 2453-711X 
significant negative associations with sustainability factors, with the exception of untrained teachers.

As for the relationship between the motivation for learning L2 and demotivation, the ideal L2 itself was significantly correlated with most factors of learning demotivation of L2. Knowledge of L2 showed a significant correlation with six factors of sustainability, three factors of motivation for learning L2 and five factors in L2 demotivation.

R1 life satisfaction, R2 self-composure, R3 communicative efficacy, R4 sociability, R5 metacognitive adaptation, R6 strategic competence, R7 realistic optimism, M1 ought-to L2 self, M2 ideal L2 self, M3 instrumental motivation, M4 parental support, M5 academic challenge, M6 awareness of importance, D1 compulsory EFL learning, D2 negative perception of English-speaking country, D3 unsupportive learning environment, D4 perceived inappropriateness of textbooks or tasks, D5 low self-esteem, D6 unsupportive teachers $\mathrm{N}=168,{ }^{*} \mathrm{p} \backslash .05, * * \mathrm{p} \backslash .01$.

\section{The proposed structural model}

To test the conceptual differences between the designs, the CFA was held as an initial step; he provided an acceptable model: v2 (df) $=156(12), \mathrm{p} \backslash .001$, TLI $=$ $.92, \mathrm{CFI}=.93$ and RMSEA $=.06$. This result confirmed that motivation, demotivation and resistance to L2 were independent, distinctive psychological constructs. As a second step in determining the structural relationship between learning motivation, demotivation, elasticity and L2 skill, an initial model based on previous studies of the relationship between these variables and the results of the correlation analysis was proposed. In order to use the maximum likelihood method, multidimensional normality was considered using asymmetry and kurtosis values to satisfy data requirements. Tayjasanant (2016) stated that asymmetry can not exceed the absolute value of three, and the kurtosis can not exceed an absolute value of ten. In accordance with these requirements, the levels were met with an asymmetry of $=-1.90$ and an excess of 5.71 .

The initial model began with a general sustainability that affects the motivation and demotivation of L2 (Kim and Kim 2017) before focusing specifically on training L2.

The impact of the motivation for learning and demotivating L2 on L2 knowledge was revealed in previous studies (Do“rnyei and Ushioda 2013, Lamb 2012). In the hypothetical initial model, factors of motivation, demotivation and resistance to L2 were considered using three questions, each of which has the greatest value of the load factors (Mulaik and Millsap 2000). An analysis of the same number of elements for each factor allows for a systematic analysis, since each factor has an equal weight. In'nami and Koizumi (2011) refer to the Tucker-Lewis index (TLI), the comparative fitness index (CFI) and the mean square approximation error (RMSEA) as the most useful and relevant indices for studying language learning. In general, TLI and CFI values greater than 0.95 , as well as RMSEA values of less than 0.6 , are considered as acceptable model criteria (Ockey and Choi 2015). However, this model showed a poor approach: v2 $(\mathrm{df})=1473.46(166), \mathrm{p} \backslash .001$, TLI $=.63$; CFI $=.68$; RMSEA $=.10$. 
Table 1 Associations between resilience, L2 learning motivation, L2 learning demotivation, and proficiency

\begin{tabular}{|c|c|c|c|c|c|c|c|c|c|c|c|c|c|c|c|c|c|c|c|c|}
\hline & RI & $\mathrm{R} 2$ & R3 & R4 & $R 5$ & Ro & $\mathrm{RT}$ & MI & $M 2$ & $M B$ & $M 4$ & MS & M16 & D! & D2 & D3 & D4 & $D S$ & $\bar{D} 6$ & $\begin{array}{l}\text { Profi } \\
\text { ciency }\end{array}$ \\
\hline $\mathrm{Rl}$ & - & .2040 & .224 & .3844 & .1844 & $.31^{40}$ & $.49^{44}$ & $.11^{144}$ & $.18^{44}$ & .04 & .02 & .1944 & .03 & \begin{tabular}{l|}
$.14^{44}$ \\
\end{tabular} & $\cdot .13^{4 *}$ & .02 & $.10^{404}$ & \begin{tabular}{l|l}
.1544 \\
\end{tabular} & .074 & $.17^{40}$ \\
\hline$\overline{R 2}$ & & - & .2044 & .174 & .374 & .284 & .274 & .04 & $.11^{44}$ & .01 & .04 & $.13^{44}$ & $.08^{4}$ & .07 & .01 & .01 & .01 & $.10^{40}$ & .01 & .06 \\
\hline$\overline{R 3}$ & & & - & .274 & $.41^{14}$ & $.47^{44}$ & .234 & .01 & $.17^{44}$ & .05 & .01 & $.16^{44}$ & .06 & \begin{tabular}{|l|}
$.13 \% 4$ \\
\end{tabular} & $.11^{4 *}$ & .03 & .03 & $\begin{array}{l}.10^{40} \\
\end{array}$ & .00 & $.12^{44}$ \\
\hline$R 4$ & & & & - & $.190^{40}$ & .344 & .364 & $.18^{44}$ & $.16^{44}$ & .01 & $.155^{40}$ & $.10^{44}$ & .1344 & \begin{tabular}{|l|}
.1744 \\
.174
\end{tabular} & $.23^{4 *}$ & $.12^{24}$ & $.13{ }^{4 * 4}$ & $\begin{array}{l}.12^{24} \\
\end{array}$ & .03 & $.16^{64}$ \\
\hline$\overline{R S}$ & & & & & - & $34^{40}$ & .274 & .01 & .254 & $.11^{40}$ & .03 & .2644 & .01 & $\begin{array}{ll}.12{ }^{4} \\
\end{array}$ & $.166^{40}$ & .04 & $.070^{4}$ & .06 & .01 & $.17^{44}$ \\
\hline R6 & & & & & & - & .2844 & .03 & .2640 & .04 & .04 & $.16^{40}$ & .02 & \begin{tabular}{ll|}
$.114^{4}$ \\
\end{tabular} & $.08^{4}$ & .02 & .05 & $.19^{404}$ & .01 & $.17^{40}$ \\
\hline $\mathrm{R} 7$ & & & & & & & - & .05 & $.27^{4 \%}$ & .06 & .02 & $.25^{40}$ & $.08^{4}$ & \begin{tabular}{l|}
. \\
$.14^{44}$
\end{tabular} & $.11^{* *}$ & .02 & .004 & .1 .46 & .05 & $.11^{4 *}$ \\
\hline MI! & & & & & & & & - & .02 & $.45^{40}$ & .364 & .204 & .544 & $21^{404}$ & $16^{\circ 4}$ & $.12^{44}$ & .074 & $.260^{64}$ & .074 & $.10^{44}$ \\
\hline $\mathrm{N} / 2$ & & & & & & & & & - & $.16^{40}$ & .06 & $.45^{44}$ & .01 & \begin{tabular}{ll|}
. \\
.2946 \\
\end{tabular} & $.24^{4 *}$ & .02 & $.09^{4}$ & $360^{\circ}$ & $.077^{4}$ & .2944 \\
\hline$M B$ & & & & & & & & & & - & .284 & .344 & $399^{40}$ & $.13^{444}$ & $.10^{404}$ & .02 & .074 & $.18^{84}$ & $.13^{404}$ & .05 \\
\hline $\mathrm{N} / 4$ & & & & & & & & & & & - & $.166^{44}$ & .3640 & $.160^{64}$ & $.16^{404}$ & $.12^{44}$ & .03 & $.14^{44}$ & .074 & .00 \\
\hline MIS & & & & & & & & & & & & - & .1944 & $\begin{array}{l}. \\
.214^{44}\end{array}$ & .204 & .01 & $.12^{4 *}$ & $.12^{24}$ & .01 & $.14^{4 *}$ \\
\hline $\mathrm{N} 16$ & & & & & & & & & & & & & - & $.23^{44}$ & $.18^{44}$ & .1544 & .074 & $.21^{144}$ & .06 & .03 \\
\hline D! & & & & & & & & & & & & & & - & $36^{64}$ & .2944 & $.44^{4 *}$ & $.444^{44}$ & .254 & $.21^{40}$ \\
\hline$D 2$ & & & & & & & & & & & & & & & - & $.33^{44}$ & $.23^{4 * 4}$ & $.244^{40}$ & $.10^{404}$ &. $.11^{40}$ \\
\hline$D 3$ & & & & & & & & & & & & & & & & - & $.32^{4 *}$ & $.200^{40}$ & $37^{40}$ & .04 \\
\hline$D 4$ & & & & & & & & & & & & & & & & & - & $.344^{4}$ & $43^{404}$ & $.10^{44}$ \\
\hline$D j$ & & & & & & & & & & & & & & & & & & - & $32^{4+4}$ & $.22^{44}$ \\
\hline$D G$ & & & & & & & & & & & & & & & & & & & - &. $.11^{40}$ \\
\hline Proficiency & & & & & & & & & & & & & & & & & & & & - \\
\hline
\end{tabular}

For this reason, the hypothetical model has been changed to the one in which there is a straight path between the sustainability and motivation of learning L2, as well as five factors (stability communication, must correspond to L2 itself and academic motivation to motivate L2 training, and the negative perception of Englishspeaking countries and untrained teachers for the demotivation of L2) were removed. The reasons for this modification of the model were as follows:

1 Removing Learning Motivation Variables L2, "Ideal L2 Self" (M2) and "Academic Motivation" (M5): The goal of learning English is to get safe work, which is an instrumental goal. Given that applicants are now faced with the worst job prospects (KSIS 2017), it is difficult for them to create ideal L2 self-ads or to support academic motivation.

2 Removing the demotivation variables L2, Negative Perception (D2) and Immunity Teachers (D6): IKTU students believe that interacting with native speakers is an ideal opportunity to improve the practical skills of the English language; these students can constantly seek ways to communicate with native speakers by visiting English-speaking countries (Cho 2015). Given this, it seems unlikely that a negative 
perception of English-speaking countries and an inappropriate L2 teacher may be one of the variables in the demotivation of L2 training.

3 Elimination of the impact of sustainability on learning motivation L2: Stability did not predict the motivation for learning L2: $\mathrm{b}=.00, \mathrm{p}$ [.05. Sustainability is more often associated with recovery from adverse effects (Cicchetti 2010, Luthar et al., 2000), which means that this design is more closely related to the demotivation or re-motivation of learning L2 than the motivation for learning L2 as such.

4 Removing the sustainability variable "Sociability" (R4): in the educational context, which encourages competitiveness as a way to achieve higher test scores and better jobs (Park 2009), students pay more attention to their own personal growth than on mutual cooperation. For this reason, sociability can be seen as a distraction, and not as a help in learning.

Thus, the straight path between training motivation and L2 resistance, as well as several factors in these designs, have been removed to improve the fit of the model, based on the theoretical considerations explained above.

\section{Discussion}

The purpose of this study is to study the constructions of motivation, demotivation and stability in L2 by using a quantitative approach. To determine the structural relationship between the motivation of learning, demotivation and the sustainability of L2, the variables in each design have been refined, eliminating some factors. It was found that the motivation for learning L2 consists of six subcomponents: self-esteem L2, ideal self L2, instrumental motivation, parental support, academic challenge and awareness of importance. It was also found that the demonization of L2 training includes six components: a negative perception of English-speaking countries, compulsory EFL training, perceived discrepancy of textbooks or tasks, low self-esteem, inappropriate learning environment and untrained teachers. To ensure sustainability, the following seven designs were defined: life satisfaction, communicative, communicative effectiveness, self-sufficiency, strategic competence, metacognitive adaptation and realistic optimism.

\section{Bibliographic references}

CICCHETTI, D. 2010. Resilience under conditions of extreme stress: A multilevel perspective. In: World Psychiatry, n. 9(3), pp. 145-154. ISSN · 1723-8617.

CONNOR, K.M. - DAVIDSON, J.R. 2003. Development of a new resilience scale: The Connor-Davidson resilience scale (CDRISC). In: Depression and Anxiety, $\mathrm{n}$. 18(2), pp. 76-82. ISSN: 2167-1044.

CSIZÉR, K. - KORMOS, J. 2009. Learning experiences, selves and motivated learning behaviour: a comparative analysis of structural models for Hungarian secondary and university learners of English. In: Motivation, language identity and the L2 self: Multilingual Mattters, Bristol, pp. 98-117. ISBN 9781847691286.

DIKA, S.L. - SINGH, K. 2002. Applications of social capital in educational literature: A critical synthesis. In: Review of Educational Research, n. 72(1), pp. 3160. ISSN: 0034-6543.

DO"RNYEI, Z. 2007. Research methods in applied linguistics. New York: Oxford University Press. ISBN: 978-0194422581.

DO“RNYEI, Z. 2009. The L2 motivational self system. In Z. Do“rnyei \& E. Ushioda (Eds.), Motivation, language identity and the L2 self (pp. 9-42). Bristol: Multilingual Matters. ISBN: 9781847691286.

DO"RNYEI, Z. - USHIODA, E. 2013. Teaching and researching motivation (2nd ed.). Harlow: Longman. ISBN: 9781408205020.

FALOUT, J. - ELWOOD, J. - HOOD, M. 2009. Demotivation: Affective states and learning outcomes. In: System, n. 37, pp. 403-417. ISSN: 0346-251X. 
GARDNER, R.C. 2001. Integrative motivation and second language acquisition. In Z. Do"rnyei \& R. Schmidt (Eds.), Motivation and second language acquisition (pp. 119). Honolulu: University of Hawaii Press. ISBN: 9781847691286.

GARDNER, R.C. 2010. Motivation and second language acquisition: The socioeducational model. New York: Peter Lang Inc. ISBN: 978-1433104596

HIGGINS, E.T. 1998. Promotion and prevention: Regulatory focus as a motivational principle. In: Advances in Experimental Social Psychology, n. 30, pp. 1-46. ISSN: 0065-2601.

HU, R.J.S. 2011. The relationship between demotivation and EFL learners' English language proficiency. In: English Language Teaching, n. 4(4), pp. 88. ISSN 19164742.

IN'NAMI, Y. - KOIZUMI, R. 2011. Structural equation modeling in language testing and learning research: A review. In: Language Assessment Quarterly, n. 3, pp. 250 276. ISSN: 1543-4303.

JUNG, S.K. 2011. Demotivating and remotivating factors in learning English: A case of low level college students. In: English Teaching, n. 66(2), pp. 47-72. ISSN: 11758708 .

KIKUCHI, K. 2013. Demotivation in the Japanese EFL context. In M. T. Apple, D. Da Silva, \& T. Fellner (Eds.), Language learning motivation in Japan (pp. 206-224). Bristol: Multilingual Matters. ISBN: 978-1783090495.

KIKUCHI, K. 2015. Demotivation in second language acquisition: Insights from Japan. Bristol: Multilingual Matters. ISBN: 9781783093946.

KIM, T.Y. 2012. The L2 motivational self system of Korean EFL students: Crossgrade survey analysis. In: English Teaching, n. 67(1), pp. 29-56. ISSN: 1175-8708.

KIM, T.Y. - KIM, Y.K. 2017. The impact of resilience on L2 learners' motivated behaviour and proficiency in L2 learning. In: Educational Studies, n. 43(1), pp. 1-15. ISSN: 0305-5698.

KIM, T.Y. - LEE, H.S. 2014. Korean junior high and high school students' English learning motivation, demotivation, resilience, and English proficiency. In: The Journal of Foreign Studies, n. 29, pp. 11-41. ISSN: 2005-2464.

KORMOS, J. - KIDDLE, T. - CSIZE'R, K. 2011. Systems of goals, attitudes, and self-related beliefs in second-language-learning motivation. Applied Linguistics, n. 32(5), pp. 495-516. ISSN · 0142-6001.

LAMB, M. 2012. A self system perspective on young adolescents' motivation to learn English in urban and rural settings. In: Language Learning, n. 62(4), pp. 997-1023. ISSN:1467-9922.

LUTHAR, S.S. - CICCHETTI, D. - BECKER, B. 2000. The construct of resilience: A critical evaluation and guidelines for future work. In: Child Development, n. 71(3), pp. 543-562. ISSN:1467-8624.

MADDI, S. 1999. Comments on trends in hardiness research and theorizing. In: Consulting Psychological Journal, n. 51(2), pp. 67-71. ISSN: 1065-9293.

MARTIN, A.J. - MARSH, H.W. 2009. Academic resilience and academic buoyancy: Multidimensional and hierarchical conceptual framing of causes, correlates and cognate constructs. In. Oxford Review of Education, n. 35, pp. 353-370. ISSN: 03054985.

MASTEN, A.S. - CUTULI, J.J. - HERBERS, J.E. - REED, M.G. 2011. Resilience in development. In S. J. Lopez \& C. R. Snyder (Eds.), The Oxford handbook of positive psychology (pp. 117-131). New York: Oxford University Press. ISBN: 0195135334.

MULAIK, S.A. - MILLSAP, R.E. 2000. Doing the four-step right. In: Structural Equation Modeling, n. 7(1), pp. 36-73. ISSN: 1070-5511.

OCKEY, G.J. - CHOI, I. 2015. Structural equation modeling reporting practices for language assessment. In: Language Assessment Quarterly, n. 12(3), pp. 305-319. ISSN: 1543-4303. 
OLSSON, C.A. - BOND, L. - BURNS, J.M. - VELLA-BRODRICK, D.A. SAWYER, S.M. 2003. Adolescent resilience: A concept analysis. In: Journal of Adolescence, n. 26(1), pp. 1-11. ISSN: 0140-1971.

OXFORD, R.L. 2016. Toward a psychology of well-being for language learners: The 'EMPATHICS' vision. In T. Gregersen, P. MacIntyre, \& S. Mercer (Eds.), Positive psychology and language learning (pp. 10-87). Bristol: Multilingual Matters. ISBN 9780230301146.

OXFORD, R.L. - MENG, Y. - ZHOU, Y. - SUNG, J. - JAIN, R. 2007. Uses of adversity: Moving beyond L2 learning crisis. In A. Barfield \& S. Brown (Eds.), Reconstructuring autonomy in language education: Inquiry and innovation (pp. 131142). London: Palgrave Macmillan. ISBN 978-0-230-59644-3.

PINTRICH, P.R. 2003. A motivational science perspective on the role of student motivation in learning and teaching contexts. In: Journal of Educational Psychology, n. 95(4), pp. 667-686. ISSN: 0022-0663

PLONSKY, L. 2015. Advancing quantitative methods in second language research. New York: Routledge. ISBN 9781317974093.

SAKAI, H. - KIKUCHI, K. 2009. An analysis of demotivators in the EFL classroom. In: System, n. 37(1), pp. 57-69. ISSN: 0346-251X.

SHAKH, M. 2016Teachers' Code Switching and English Language Proficiency in Students. In: The International Journal of Communication and Linguistic Studies, n. 14(3), pp. 27-33. ISSN 2372-479X.

SHIN, W.Y. - K IM, M.G. - KIM, J.H. 2009. Developing measures of resilience for Korean adolescents and testing cross, convergent, and discriminant validity. In: Studies on Korean Youth, n. 20(4), pp. 105-131. ISSN 1225- 0201.

TAGUCHI, T. - MAGID, M. - PAPI, M. 2009. The L2 motivational self system among Japanese, Chinese, and Iranian learners of English: A comparative study. In Z. Do"rnyei \& E. Ushioda (Eds.), Motivation, language identity and the L2 self (pp. 6697). Bristol: Multilingual Matters. ISBN: 9781847691286.

TAYJASANANT, C. 2016. Changes in Foreign Language Learning Strategies Used by Thai University Students. In: The International Journal of Communication and Linguistic Studies, n. 14 (2), pp. 49-66. ISSN 2372-479X.

TRANG, T. - BALDAUF, R. 2007. Demotivation: Understanding resistance to English language learning-the case of Vietnamese students. In: The Journal of Asia TEFL, n. 4(1), pp. 79-105. ISSN, 1738-3102.

Words: 5534

Characters: 37234 (20,68 standard pages)

Prof. Gulzhan Isatayeva, Cand. of Ec. Sc.

South-Kazakhstan State Pedagogical University

13, A. Baitursunov st. Shymkent

Kazakhstan

Gulzhan.isatayeva@mail.ru

Prof. Ileshan Smanov, Dr.

South-Kazakhstan State Pedagogical University

13, A. Baitursunov st. Shymkent

Kazakhstan

Ileshan.smanov@mail.ru

Dinara Mutanova, PhD Doctor student

Ahmet Yassawi International Kazakh-Turkish University,

19, B. Sattarkhanov. St. Turkestan

Kazakhstan 
dinar_a86@mail.ru

Nursaule Aytbayeva, candidate of philological sciences, assistant professor, Ahmet Yassawi International Kazakh-Turkish University, 19, B. Sattarkhanov. St. Turkestan

Kazakhstan

nursaule_1965@mail.ru

Zhanar Saduova, candidate of pedagogical sciences, assistant professor, Ahmet Yassawi International Kazakh-Turkish University,

19, B. Sattarkhanov. St. Turkestan

Kazakhstan

saduova1977@list.ru

Saltanat Beissembayeva, candidate of philological sciences Ahmet Yassawi International Kazakh-Turkish University, 19, B. Sattarkhanov. St. Turkestan

Kazakhstan

saltanat_rb@mail.ru 